\title{
Are individualistic attitudes killing collectivism?
}

\section{David Peetz}

Professor of Employment Relations, Centre for Work, Organisation and Wellbeing, Griffith Business School, Griffith University, Australia

\section{Summary}

This article addresses a core aspect of the question: 'is the collectivism of labour in fundamental decline?' It pays particular attention to attitudes towards collectivism using national and cross-national data on trends in dimensions of collectivism over periods of up to two decades. The data indicate that collective values and identities are today broadly as strong (or weak) as they were two or three decades ago. If individualization is the problem, then we should not look at individualization of attitudes but attempts by employers and governments to individualize the employment relationship. Union organizing strategies need to reinforce union values and build solidarities across groups which are more complex and heterogeneous than in the past.

\section{Résumé}

\section{Zusammenfassung}

\section{Keywords}

Individualization, collectivism, union strategies, union renewal, attitudes, identity, values

\section{[Corresponding author}

David Peetz, Department of Employment Relations and Human Resources, Griffith University, Brisbane QLD 4111, Australia. Email: d.peetz@griffith.edu.au.

To appear in Transfer, 16(3), 2010. 
There is a magical moment in the film Monty Python's Life of Brian, when the hero, Brian, opens his bedroom window to find the streets filled with adoring followers.

'You don't have to do this!' he shouts. 'You're all individuals!

'Yes', they chant, 'We're all individuals!'

'You're all different!'

'Yes, we are all different!' (Chapman et al., 1979)

This interchange has happened hundreds of times as social commentators, politicians and even union leaders look at masses of ordinary people and declare, 'We cannot organize the way we used to - they're all individuals now!' And perhaps people are not organized in exactly the same manner as the past. But does this mean that there has been a structural ascendancy of individualism and concomitant decline of collectivism? Does the ability of unions to achieve members' goals now rest on their ability to mobilize collective power, or on their ability to respond to individualistic needs? The decline of union density in most industrialized countries, alongside the decline in some other mass organizations such as churches and developments in mass culture, has led to claims that collectivism is on the decline and individualization has come to dominate Western societies. In the eyes of some, people are increasingly separated from the traditional ties of family, locality or class due to the individualization of inequality produced by welfare state institutions such as education. Individuals are embedded in market relations, increasingly making their own choices (experiencing 'individuation'), fashioning their own identities, and are isolated, autonomous and egocentric (e.g. Beck, 1992; see also Zoll, 1995). A separate line of argument, put forward by Robert Putnam (2000), is of decline in social capital - that is, the trust and networks upon which collective action relies evidenced in surveys and in falling membership of voluntary associations. Putnam attributed this not so much to individualization as to the expansion of television, which atomized people and weakened their social ties.

For trade unions, a fundamental individualization in society would spell doom, as their organizational basis is ultimately collectively addressing class relations. If individualism reigns supreme, then employees simply purchase union 'services' from 
unions, the price and quality of those services is what matters, and collective action is just a cost experienced by employees in obtaining union services. Other non-union providers might be able to undercut unions for services presently provided by unions. But if employees still have collective values and identities, or at least have the potential to act collectively and to be genuinely members, not purchasers, of a union, then unions are uniquely positioned to seek to mobilize and empower members. Through successful member empowerment, unionism itself might be renewed.

Several researchers have challenged the individuation thesis as lacking empirical basis, and there is much data to demonstrate the continuing salience of class in explaining income, consumption, education, health and infant mortality: 'class differences persist and have, in many respects, become sharper' (Scott, 2000). In addition, Atkinson (2007) argues forcefully there is strong reason to doubt the theoretical consistency of individuation.

My particular attention is on the attitudinal dimension - to ask, 'Are individualistic attitudes killing collectivism?' Several propositions about the individuation of society rest ultimately on changing attitudes and orientations said to arise from broader changes in society. Fundamental changes in this area would signal something happening in the core of human nature that would be extremely difficult, perhaps impossible, for unions to redress. If we really all are selfish individuals now, why would we bother with collective action? After clarifying and briefly elaborating the core concepts, I address these questions through national and cross-national data on trends in attitudinal elements of collectivism over periods of up to two decades, making use of national and international social science surveys and other studies that necessarily cover various time periods.

\section{Core concepts}

A range of writers have considered collectivism in many different ways and contexts (e.g. Devine, 2000; Hofstede, 1984; Triandis, 2001), but for our purposes here, it refers to the way in which interests, orientations and behaviours are based on predominantly group rather than predominantly individual reference points and involve cooperation with other members of that group. Collective behaviour means that short-term individual self-interest gives way to the common good, where the two 
conflict. Collectivist attitudes promote cooperation with other members of a group (or society). Individualistic attitudes, by contrast, are based on predominantly individual rather than predominantly group reference points and encourage self-referential rather than collective behaviour. At the individualist extreme all decisions are egocentric with no reference to any persons other than the selfish individual.

Importantly collectivism and individualism are points on a continuum of possibilities rather than the only two possibilities. In practice, most people exhibit some combination of individualism and collectivism in their attitudes and behaviour. If you are part of a family, you will probably behave collectively with regard to many interests of members of the family. Few people live hermitic lives with no concern for any other person. At the other extreme, few people are so committed to the interests of a family, group or society that they will subjugate the entirety of their interests and abandon their free will to the will of others.

\section{Dimensions of collectivism}

In order to examine whether collectivism is in secular decline, we should first specify what comprises collectivism - that is, dissect collective behaviour into its core dimensions. It is convenient to think of it as having three core dimensions.

The first, the attributional dimension, refers to the individualization or collectivism of needs. It is the extent to which there are needs or grievances that are felt by individuals but that are also shared by others, and therefore open to collective resolution.

The second, the attitudinal dimension, refers to the extent to which identities, values and beliefs strengthen or weaken collective orientations. It has three major elements: the extent to which individualistic or cooperative values exist or are created or reinforced; the extent to which social identities are fragmented or shared, and align with or are inconsistent with those necessary for collective action; and the extent to which group members possess beliefs of collective efficacy.

To briefly explain these in turn: where people possess cooperative values - values that promote altruistic or mutually supportive behaviour, that reinforce trust among members of the group, or that emphasize the welfare of a group as a whole, as 
opposed to that of successful individuals - then collective attitudes and the scope for collective behaviour will be strengthened. Where people share a common social identity, they are likely to act together (C Kelly and Breinlinger, 1995), but where they lack a sense of common identity they are unlikely to act together (JE Kelly, 1998). Where people possess beliefs of collective efficacy (Bandura, 1997), that is they sense agency (JE Kelly, 1998) and believe they have the power to achieve their goals through collective behaviour, they will be more likely to behave collectively. Efficacy, it should be noted, may be individual (people believe they have the capacity to achieve their objectives as individuals, referred to as self-efficacy) or collective (people believe that the group to which they belong has the capacity to achieve its objectives). Individualistic values are at odds with collective values, and what we could clumsily call 'individualistic identity' (really, anti-collectivist identity, placing identity with the employer above collective worker identity) is at odds with collective identity. However, the 'individual' and the 'collective' of efficacy are not at direct odds with each other. Workers with strong labour market power (for example, professionals or skilled workers with skills in short supply) may feel that their individual labour market power is strong enough for them to not need to exercise collective power. On the other hand, workers with low self-efficacy often have low collective efficacy, and will be reluctant to coalesce into collective organizations (unions) because they will not see that it could make a difference to them: 'a collective of self-doubters is not easily forged into a collectively efficacious force' (Bandura, 1997: 480). Efficacy, shared identities and collective values are intercorrelated and reinforce each other (C Kelly and Breinlinger, 1995).

The third, the coordination dimension refers to the creation or destruction of coordinating capacities. For reasons of space we do not focus on that dimension in this paper, but note that, again, three elements are relevant here: the existence of connections or networks (series of connections) between members of the group; the existence or otherwise of collective mobilizers who can mobilize collective cooperation; and the extent of democratic (collective) coordination versus autocratic (individual) coordination within the collective.

These three dimensions - attributional, attitudinal and coordination - shape the extent to which collective behaviour is likely to occur. How much, this in turn, 
translates into the exercise of collective power will also depend on the institutional and environmental responses to collective action. These determine opportunities for, or impediments to successful collective behaviour and exercise of collective power. The three key elements of this are: the actions of the state, including the legislative framework it creates; the behaviours of corporations and employers; and the condition of the labour market, a depressed labour market making it much harder for labour to secure its objectives. The model described above is summarized in Figure 1. The chart, read from top down, depicts the various dimensions in the sequence in which they are discussed above, but there are interactions between the various aspects (for example, collective needs are framed not just by objective circumstances but also by 'relative deprivation' (Runciman, 1972) which is understood through reference to identity; collective power shapes the institutional and economic environment (for example, by influencing the laws that are in place) and is critical in determining collective efficacy; and so on). To signify, but simplify, these interactions, the chart shows arrows in both upwards and downwards directions. 


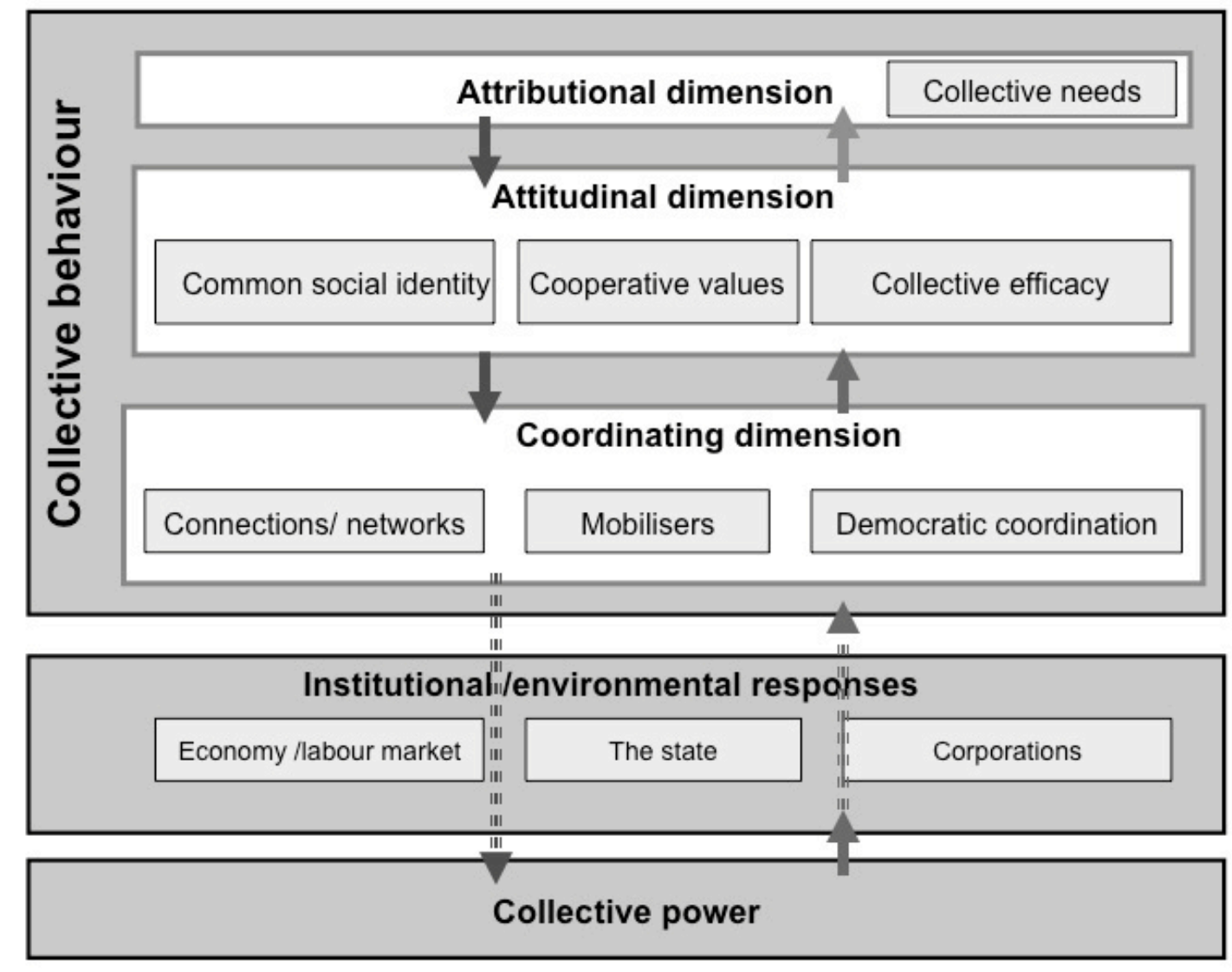

Figure 1. Dimensions of collective action and their links to collective power

\section{Collective work identities}

People typically have many complex and multifaceted identities. As Fougere points out, there may be hierarchies of identity (Fougere, 1989), which some have referred to as hierarchies of collectivism (such as family, social group and country), and people's relations with these collectives may have different characteristics (Realo et al., 1997). At work there are potentially complex, overlapping groups with which workers might identify, focusing on economic organization (the employer or industry), work organization (the work group, occupation or class), spatial location (the community or region in which people live or work) and/or labour organization (the local or national union). Unions, corporations and other collectives will each try to shape the reference groups with which people identify, for the purpose of affecting patterns of collective behaviour. Employers will seek to promote narrower ('individualistic') social identities based on workers' immediate work environment and 
their employing corporation, but these identities will also be constructed by the workers themselves (Stephenson and Stewart, 2001), while unions seek to create and strengthen employee identifications with occupation, class and union and to shape expectations based on movements in community standards and inequities in the distribution of income and wealth.

While corporations seek to shift workers' identities, in the community, other identities are also developing. Valkenburg argues that people's identity is 'characterised less and less by mutual similarities and increasingly by mutual differences' as 'collective frames of reference that were based on an industrial class society, and from which people derived part of their individual and social identity, are losing their significance' (Valkenburg, 1995). In this view, personal identity and socialization is shaped by an increasing number of experiences, a result of mass communication, mass education, the welfare state and consumerism. Hence, some may argue that collectivism is in decline, or is at least no longer given by tradition or homogeneity of interests, because the old collective identities of the past have been supplanted by new individualistic identities. This might seem a contradiction - identity as part of any group is, by definition, a collective feature.

Space does not permit a discussion of the many new social identities emerging identities arising from the rise of the feminist revolution, the assertion of the legitimacy of gay and lesbian sexuality, the environmentalist movement, indigenous rights groups, the rise of dance club culture, the spread of Internet technology and more. But it is not clear that many of these new identities, if they are indeed new, would favour identification with the corporation at the expense of identification with fellow workers. They do not inherently undermine collectivism of labour - unless union behaviours themselves reject the notion that people can have multiple identities while being part of a collective of labour.

For example, young workers are often seen as being as being at the forefront of new identities. They are so obviously different to older people, and union membership is much lower amongst young workers than amongst middle aged and older workers. But is this a sign of the effect of identities shifting away from collectivism? Data have been collected in several countries (including Britain, Canada, Australia and New Zealand) on young people's relative desire for union 
membership. They show that this desire is just as high amongst the young as other age groups. The main differences are that young workers are less likely to know about unions, or to have the opportunity to belong to one - because they tend to work in casual jobs, in smaller workplaces and in weakly unionized industries, and to be in each job for a relatively short time (see various studies in Freeman et al., 2007; also Freeman and Diamond, 2003). They are also more vulnerable to exploitation and intimidation. Young US workers have higher confidence in unions than older ones (Levine et al., 2008).

This is not to deny the existence of forces in society that aim to reduce common social identity amongst workers, including corporate programmes of cultural control (Willmott, 1993) and institutional bias in the media. Moreover, there have been important changes in the labour market. Traditional 'blue-collar' (manual) jobs, conventionally seen as being the bastion of the working class, have been in structural decline and white-collar jobs have equally grown. Union membership has declined in most industrialized countries, and so the proportion of new workers entering the labour market who are socialized by parents or peers to accept collective identifications must also have declined. So we might easily expect to see an abandonment of working class identification and the rise of individualistic identities as more and more people think of themselves as middle class and cast aside old working class identities and ideologies.

But has this happened? In Britain, the blue-collar share of jobs fell from 62 percent in 1961 to 41 percent in 1991 and a mere 29 percent in 2006 (Learning and Skills Council, 2007; Savage, 2002). But over that 30-year period, the net shift in class identity was very minor. The first national survey on British voting behaviour, in 1961, found 63 percent of people claimed to be working class. By 1991, in the British Social Attitudes Survey, some 64 percent reported thinking of themselves as working class (Savage, 2002). By 2005, the proportion identifying as working class had fallen to 57 percent, still only 6 percent below the 1961 figure despite the halving of bluecollar jobs (Arnot, 2009).

In the United States, where the phrase 'working class' appears almost absent from public discourse, the general social survey showed with a differently worded question that in 1976, 51 percent of Americans thought of themselves as either 
working class or lower class. (This comprised 46 percent working class and 4 percent lower class.) In 2006, the same survey showed 52 percent identifying as either working class or lower class (comprising 45 percent working class and 6 percent lower class). Within this period numbers had fluctuated from year to year but always within a range of between 48 and 55 percent expressing working or lower class identity.

In Canada, the proportion identifying as working or lower class was 36 percent in 1980 (34 percent working class and 1 percent lower class), and still 36 percent in 1995 (33 percent working class and 3 percent lower class). Middle class identity was 62 percent in both years.

In Australia, between 1979 and 2007, the proportion of national survey respondents defining themselves as working class or lower class temporarily grew from 40 percent, to the low 50s in the 1980s and 1990s, then back to 44 percent by 2007 , while those defining themselves as middle class fell slightly from 56 percent to 53 percent over those 28 years (Aitkin, 1982; McAllister and Clark, 2008).

In short, while 'blue-collar' jobs have sharply declined, the notion of 'working class' has been relatively stable within some fluctuating bounds. Differences in class identity between countries seem more notable than differences over time. The stability of working class identification over time is remarkable not only because of the decline of blue-collar employment but also because, as US historian Rachleff says, 'We are bombarded by so much popular culture that tells us continually that this is a middle-class society' (Heath, 1998). The concept's popular resilience is probably partly because of the character of many expanding elementary and intermediate white-collar jobs - there is not much middle class glamour at the checkout counter, behind the hamburger hotplate or in the call centre factory.

This is not to say that giving a 'working class' response to a forced-choice survey question is equivalent to an unambiguous or deeply thought position on class. Less still is a specifically 'working class' identity (as opposed to an identity with a particular occupation or group of workers) necessary for collective action to occur. Savage et al argue, for example, that both 'middle class' and 'working class' identifiers see themselves as 'ordinary' people, with the result that 'the potential relevance of class 
is re-introduced through the back door' of 'ordinariness' (Savage et al., 2001). Moreover, as Donaldson points out, 'the intensity of class feeling varies as conditions change, battles are won and lost and strength of the contending classes varies' (Donaldson, 2006). But if societal individualization were really breaking down the prospects for collectivism through changing people's orientations, we would expect that the first thing to go would be working class identity. That people can still respond in these terms to survey interviewers says something about the limits of individuation.

So, despite the efforts of corporations as employers, as advertisers and as mass media, and despite changes in the nature of occupations, workers' social identification with each other does not appear fundamentally weaker now than it was over a quarter of a century ago. That said, the writers on 'individualization' of society have an important point - while the increasing diversity of workers does not mean the demise of collectivism in employment relations, it does mean that the collective organization of workers has to take account of this increasing diversity (Valkenburg, 1995; Zoll, 1995). This means major changes in how unions organize, communicate with and relate to their members, as discussed elsewhere in this issue (see the article by Dufour and Hege, in this issue).

\section{Collective values}

One important aspect of collectivist values is attitudes towards equality and inequality. Although collectivist values do not require that all people receive equal benefits, they do imply that all members of a group should receive benefits and that they should not be concentrated in the hands of a few. For the rugged individualist, personal freedom is what matters, and equality is not necessarily relevant. One way of testing whether individuation is leading to fundamental changes in collectivist attitudes is to examine people's relative preferences for those two ideals. The World Values Survey has done this over two decades, with a rather long question that asks people to choose between two statements that commence with 'both freedom and equality are important, but if I were to choose one or the other' and then diverge into: 'I would consider personal freedom more important, that is, everyone can live in freedom and develop without hindrance' or 'I would consider equality more important, that is, that nobody is underprivileged and that social class differences are 
not so strong.' It is a question that elicits different responses between countries reflecting national cultures (Americans are more likely than anyone else to rate 'freedom' more important) but also differences in objective situations in the countries (Norwegians also score freedom relatively highly, presumably as many feel they have lots of equality already). But what is interesting is how responses to this choice change over time. This question was asked in each of three waves of the project, in 1981-83 (wave 1), 1989-92 (wave 2) and 1999-2001 (wave 4). Different countries participated in different waves, but a comparison of patterns over these periods is shown in Table 1. If individualization were leading to the death of collectivist attitudes, we would expect to see a significant and consistent shift towards the 'freedom' response from one wave to the next.

\section{-- Table 1 around here --.}

The data provide no support for that thesis. Amongst the 16 countries that participated in both the first and second waves, support for freedom rose in seven countries but support for equality rose in nine. Amongst the 24 in both the second and fourth waves, support for freedom rose by at least one percentage point in eight countries but support for equality rose by that margin in 12. And amongst the 12 countries in both the first and fourth waves, almost two decades apart, support for freedom rose by that margin in five countries but support for equality rose that much in eight. (Varying numbers of respondents saying 'neither' or 'don't know' explain why in some countries support for both concepts could rise - or fall.) In each period, the average support for equality rose by more than did the average support for freedom.

Austen (2002) undertook a somewhat different study, based on hypothetical questions about earnings distributions in several countries (Germany, UK, US, Australia, Hungary, Poland) in the International Social Survey Program (ISSP). She found that, on average, voters' tolerance of inequality increased over the period 1987-92, but also that the degree of inequality tolerated was positively related to actual inequality and that the increase in actual inequality was considerably greater 
than what people were willing to tolerate. Moreover, except in Germany, most of the increase in tolerance of inequality was due to changes in attitudes of the elite: amongst 'ordinary workers' there was little net movement (inequality tolerance decreased in two countries, increased slightly in two and was unchanged in one) (Austen, 2002). American public attitudes against wide differentials between the highest income earners and the rest appeared to harden from 1987 to 1999 (Osberg and Smeeding, 2006). Listhaug and Aalberg (1999) examined attitudes to inequality in eight countries against ISSP questions from 1985 and 1987 to 1992, and concluded the 'main empirical finding is of stability, but with a slight increase in the pro-inequality direction'. Unlike Austen, they found no divergence in trends by class. These studies and other surveys (e.g. GlobeScan/BBC World Service, 2009; International Labour Office, 2004) also show that in most counries there is majority support for government action to reduce inequality.

The World Values Study also included a question asking people to choose a point on a 10-point scale between two questions that measured aspects of individual and collective responsibility: 'people should take more responsibility to provide for themselves' or 'the government should take more responsibility to ensure that everyone is provided for'. The question was asked in waves 2, 3 (1995-1998) and 4. If individuation were displacing collective attitudes, then we would expect support for collective responsibility via the state to fall consistently. This question showed more uniform trends between countries than did the freedom versus equality question, but notable volatility between periods. Thus in 18 out of the 19 countries in both waves 2 and 3, support shifted towards the notion of greater government responsibility over that period. By contrast, between waves 3 and 4, support shifted back towards selfresponsibility in 17 out of the 20 countries. Overall, in the decade or so between waves 2 and 4, support shifted towards government responsibility in 16 countries, and towards self-responsibility in 14 (calculated from Ifo Institute for Economic Research, 2008). The average movement across all countries with data for that period was a very slight shift towards greater government responsibility. Again, there is little sign here of a secular decline in collectivist attitudes. 
More specifically on matters regarding unions, although attitudes may fluctuate over long periods of time, the data do not suggest an inexorable decline in orientations towards organized labour. In, for example, the country with the most precipitous long-term decline in union density, the United States, Panagopoulos and Francia (2008) have collated a wealth of data that shows relatively little difference between general attitudes to unions in recent times and those of several decades ago (at least, by comparison with the drop in union density). For example, general 'approval' of labour unions in Gallup surveys averaged around 65 percent in the 1940s, dropped to 57 percent in the 1980s but was back up to 60 percent through the first half of the 2000s. 'Warmth' towards unions on the election study's widely used 'thermometer', at 58 on a scale of 0-100 in 2004, was the same level as in the 1960s. Gallup questions on whether people's sympathies were typically with unions or companies during disputes showed attitudes no less positive in 2005 than in the 1990s or even 1950s, and on specific major strikes since the mid-1980s perceptions were more pro-union than during comparable major disputes over the preceding half century (Panagopoulos and Francia, 2008). Australian data tend to show a significant decline in sympathies towards trade unions through the decades to the early 1980s, but (depending on which measure is used) stability or improvements since then (Peetz, 2002).

Another aspect of collectivist values is trust. A comparison of trends in general trust across nine countries was undertaken by Patulny (2004), using data from the World Values Study on whether respondents thought in general, most people can be trusted (as opposed to believing one needed to be careful with most people). It showed that trust increased between the 1980s and 2000 in Norway, the Netherlands, Germany, Austria and Italy, but declined in the 'Anglo-liberal' countries (USA, UK, Canada and Australia). Several studies cited by Patulny showed trust to be higher when inequality is lower, and so he found trust was highest in the socialdemocratic countries of Norway and Netherlands. In separate research, Denmark also exhibited increasing levels of social trust over the 1980s and 1990s (Torpe, 2003). Patulny also noted that declines in trust in the Anglo-liberal countries occurred after cutbacks in welfare programmes had occurred, suggesting the hypothesis that 'cutbacks and punitive changes to welfare erode bridging social capital' (Patulny, 2004). 
None of the above should be taken as indicating relentless stability across attitudes in industrial societies over many years. You need only watch an old television show or news report or ask your parents about their childhood (reminisce about your own, if you are old enough) to remind yourself of how much society has changed. But the changes in attitudes have mainly been in areas that do not fundamentally alter the potential for collective attitudes and behaviour - they are in areas such as recognition of women's rights, abilities and equality, greater acceptance of homosexuality, environmental issues and the like. Inglehart (2008) has developed a longstanding thesis that Western societies are moving from 'materialist' to what he grandly (and perhaps simplistically) calls 'post-materialist' values. It shares with Beck and others an emphasis on individual 'self-expression' and wellbeing, and implies that 'the main axis of political conflict should gradually shift from class-based issues such as income redistribution and state ownership of industry toward increasing emphasis on quality of life issues' (Inglehart, 2008). Inglehart discloses, however, that his index of 'post materialist' values is positively correlated with trust, willingness to join boycotts, willingness to sign a petition and attending meetings to protect the environment (Inglehart, 2008), all characteristics conducive to collective behaviour. So whatever shifts are being measured here, they do not necessarily imply a decline in the potential for collective behaviour.

As well as looking at reported attitudes, we can also consider actual behaviour that relates to collectivist attitudes. One indicator of collectivist values is volunteering activity, a form of cooperative behaviour that involves forgoing one's own time to benefit others. Certainly, Putnam claimed sustained declines in volunteering in the USA since 1965. Yet other international evidence overall does not support that thesis. National and multinational time use surveys also reveal volunteering activity increased between 1987 and 1997 (Patulny, 2004; Wilkinson and Bittman, 2002). Canadian opinion poll data from 1987 to 2000 showed no evidence of any decline in volunteering over that period (Mendelsohn, 2002). Volunteering was also generally stable or, mostly, increasing in other countries for which data were available: the UK, the Netherlands and Japan (Healy and Côté, 2001; Patulny, 2004). In Australia the number of volunteers increased from 24 percent of the population in 1995 to 32 percent in 2000, and then to 35 percent in 2006, though the median number of hours volunteered fell (Australian Bureau of Statistics 4441.0). Overall, the figures do not 
lend credence to the view that volunteering behaviour is in any broad, structural decline. The opposite appears to be the case in many countries outside the US.

Another indicator of collective behaviour is membership of associations. This is really more about coordinating capacity than collectivist attitudes but is notable because if general collectivist attitudes were collapsing then associational membership should too. It is tempting to see the decline in union membership as part of a broader problem of declining organizational membership. Putnam's (2000) thesis was based in part on his finding that involvement in organizations has decreased in the USA. Likewise, in Australia, some traditional community organizations experienced significant falls in membership leading up to the 1990s, though engagements of a more ephemeral nature partly offset this (Cox, 2000). However, Healy and Côté (2001) found that - aside from political parties, unions and the church - association membership has mostly been stable or increased in the Netherlands, Sweden, Japan, France and Germany, though in several countries 'participation seems to have shifted towards more informal and transient affiliations'. Hall (1999) found no decline in association membership in the Britain. Patulny (2004) using the World Values Survey, found rising voluntary association membership in the Netherlands, Norway, Australia, Canada, the USA, Austria and Italy (but the reverse in the UK and Germany). Welzel et al. (2005) disaggregate those World Values Survey data to show that across 12 industrialized societies, membership of utilitarian associations (e.g. unions, professional associations or political parties) was quite stable from 1980 to 1990 and 2000, while membership of 'sociotropic' associations (charity, environmental or cultural associations) grew significantly. They also identified significant growth in 'elite challenging activities' (participating in petitions, demonstrations, boycotts, wildcat strikes and building occupations) over that period, all of them having collectivist overtones.

\section{Efficacy}

The data so far indicate that the orientations towards collective behaviour, as indicated by collective values and identities, are broadly as strong (or weak) as they were two or three decades ago. It should be recalled, though, that our attitudinal dimension also had a third element: beliefs about collective efficacy. Workers might 
feel that collective action is still a good thing, but may be less confident in its ability to achieve its aims. Here, we have much more difficulty in collecting data.

Certainly, there is no shortage of objective evidence about the decline of union power, as evidenced by declining union density and collective bargaining coverage (e.g. Visser, 2007). But the evidence on perceptions of that is much rarer. Australians are less likely these days to say that unions have too much power (McAllister and Clark, 2008; Peetz, 2002), Americans tend to show greater stability over time (Panagopoulos and Francia, 2008), but the extent to which these trends are due to shifts in norms as opposed to in perceptions of the location of power is unclear. In the US, confidence in trade unions has declined probably more than any other aspect of trade union attitudes: from an average of 36 percent reporting 'quite a lot' or 'a great deal' of confidence in them in the 1970s, to 28 percent in the 1980 s and 24 percent in the 2000s (Gallup, 2010) - but is this because respondents feel unions are less powerful or because they are worse run? In Australia, unions are thought to be better run now, at least as evidenced by trends in whether unions are seen to be looking after their members (Bearfield, 2003). Bryson (2001) found no decline in perceptions of union effectiveness among employees in unionized British workplaces (measured by whether employees thought the union was doing its job well) over numerous surveys between 1983 and 1998. Perhaps there is a dissonance between how members perceive unions in their own unionized workplace and the broader power of unions. Whatever the reason, there is a need for more longitudinal research before we can draw firm conclusions about perceptions of collective efficacy.

\section{If it's not individualistic values and identities ...?}

The discourse of individualism has salience because most people simultaneously possess individualistic and collectivist characteristics, and are neither totally selfcentred nor totally altruistic. As the crowd tells Brian, 'we're all different!' - and then to highlight the contradictions in this, a little voice at the back pipes up: 'I'm not!' Amongst our individualities we also all share various degrees of common needs and values. 
For some union leaders, the discourse of individualism might be attractive because it provides an easy excuse for the failure to renew; or because it fits with the dominant, market-based view of society, in which all relationships are transactional, including that between union and employee; or because countless marketers, advertisers and corporate image makers glamourize individualism as a selling point for their product or company. But the discourse does not match what the data tell us about individualistic attitudes.

The contrast of the large drop in density and coverage with the considerably greater stability in collective values and collective identities suggests that if individualization is the problem, then we should not look at individualization of attitudes but individualization in the employment relationship through the decisions of specific actors. By individualization in the employment relationship, we mean the diminution or removal of collective mechanisms for determining the employment contract - that is, of collective bargaining, union representation and labour laws that provide collective protections for workers, so that wages and conditions are individually 'negotiated' or, more commonly, unilaterally determined by management.

There is substantial evidence from a range of countries (though particularly the anglophone ones) of increased employer and state aggressiveness towards unions and collective organization of labour, through the passage of anti-labour legislation and greater employer opposition to union organizing attempts and attempts to hire workers on 'individual contracts' or other non-union forms of employment (e.g. Freeman and Kleiner, 1990). Employer attitudes appear to have hardened against unions more than employee atitudes have shifted. The intensifying of competition through neoliberal reforms has probably accelerated this process. Perhaps new work technology has also tended to atomize workers (Richardson, 2008), though it also increases the prospects for employee communication and mobilization (Greene and Kirton, 2003), in part because the more people are online and involved in online organizational and political activity, 'the more they are involved in offline organizational and political activity' (Wellman et al., 2001). In several countries there is evidence of increased work pressure and a 'work-life collision', compared to earlier decades (Pew Research Centre, 2008; Pocock, 2003), and this may reduce opportunities for collective organization, though the evidence is ambivalent (Griffith 
Work Time Project, 2003). Structural changes in the labour markets have not helped unions either, though this rarely can be blamed for the whole or majority of union decline (Peetz, 1998).

None of this is to downplay the importance of promoting union values in order for labour collectivism to prosper. Without collective values and identities, collective mobilization is impossible, and in the absence of the socialization mechanisms of the past, the challenges for unions in this area are greater. They are made greater still by the large problems unions face in persuading employees that they truly can exercise power on their behalf if those employees participate in collective action. But they are not made greater by any fundamental individualization of values or destruction of collective identities in society as a whole. Institutional and economic changes in Western societies, and a failure of unions to respond adequately to those changes, have made it more difficult for labour to enact and coordinate collective action, leading to an arguable decline in its perceived efficacy. But there is nothing inherent in changing attitudes that makes collective action impossible.

The appropriate policy responses by unions, then, are not to focus increasingly on 'individualized' services, as if in a transactional relationship with the member. Instead, 'organizing' or 'democratizing' approaches to unionism that focus on placing the member, rather than the official, at the centre of union action and decision making have the potential to play an important role in union revitalization. Such approaches are important in developing a sense of collective efficacy. But they need to encompass a broader rethinking of the way in which collectivism is organized within unions. They need to reinforce union values and build solidarities across groups with more complex, heterogeneous identities than in the past. These groups have as much psychological potential for collective organization as had the members of years gone. Whether they become unionized or non-union will not be a result of some core change in values or identitities sweeping Western societies. Rather, it will be determined by the actions of unions themselves. 


\section{Acknowledgments}

Particular thanks go to Gregor Murray, Christian Dufour, Shalene Werth, CRIMT coresearchers and a host of others too numerous to name separately.

\section{Funding}

This research received no specific grant from any funding agency in the public, commercial, or not-for-profit sectors.

\section{References}

Aitkin D (1982) Stability and Change in Australian Politics. Canberra: Australian National University Press.

Arnot C (2009) No such thing as a classless society. Guardian, 7 October.

Atkinson W (2007) Beck, individualization and the death of class: a critique. British Journal of Sociology 58(3): 349-366.

Austen S (2002) An international comparison of attitudes to inequality. International Journal of Social Economics 29(3): 218-237.

Australian Bureau of Statistics (4441.0). Voluntary Work, Australia. Canberra.

Bandura A (1997) Self-efficacy: The exercise of control. New York: WH Freeman \& Company.

Bearfield S (2003) Australian employees' attitudes towards unions. Sydney: ACIRRT, University of Sydney.

Beck U (1992) Risk society: towards a new modernity. London: Sage.

Bryson A (2001) The Foundation of 'Partnership'? Union Effects on Employee Trust in Management. National Institute Economic Review 176(1): 91-104.

Chapman G, Cleese J, Gilliam T, Idle E, Jones T, and Palin M (Cartographer) (1979) Monty Python's Life of Brian [motion picture].

Cox E (2000) Making the lucky country. In: Putnam RD (ed.) Democracies in Flux: The evolution of social capital in contemporary society. New York: Oxford University Press, 333-358. 
Devine J (2000) The positive political economy of individualism and collectivism: Hobbes, Locke, and Rousseau. Politics \& Society 28(2): 265-304.

Donaldson M (2006) Class: History, Formations and Conceptualisations. University of Wollongong.

Fougere G (1989) Sport, culture and identity: The case of rugby football. In: Novitz D, Willmott B (eds) Culture and Identity in New Zealand. Wellington: GP Books, 110-122.

Freeman RB, Boxall P, and Haynes P (eds) (2007) What Workers Say: Employee Voice in the Anglo-American World. Ithaca NY: ILR Press.

Freeman RB, Diamond W (2003) Young workers and trade unions. In: Gospel H, Wood S (eds) Representing workers: Union recognition and membership in Britain. London: Routledge, 92-118.

Freeman RB, Kleiner MM (1990) Employer behavior in the face of union organizing drives. Industrial \& Labor Relations Review 43(4): 351-365.

Gallup (2010) Confidence in Institutions. Available at: http://www.gallup.com/poll/1597/confidence-institutions.aspx

GlobeScan/BBC World Service (2009) Wide Dissatisfaction with Capitalism - Twenty Years after Fall of Berlin Wall. London: BBC.

Greene A-M, Kirton G (2003) Possibilities for remote participation in trade unions: mobilising women activists. Industrial Relations Journal 34(4): 319-333.

Griffith Work Time Project (2003) Working time Transformations and Effects. Brisbane: Queensland Department of Industrial Relations.

Hall PA (1999) Social capital in Britain. British Journal of Political Science 29(3): 417-461.

Healy T, Côté S (2001) The Well-being of Nations: The role of human and social capital. Paris: OECD.

Heath RP (1998) The new working class: in a supposedly classless society, nearly half of Americans consistently identify themselves as working class. American Demographics.

Hofstede G (1984) Culture's Consequences: International differences in work-related values. London: Sage. 
Ifo Institute for Economic Research (2008) Database for Institutional Comparisons in Europe. Munich. Available at: www.cesifogroup.de/portal/page/portal/59C1D39D15DD5231E0440003BA988603+\%22I +would+consider+equality+more+important $\% 22 \& \mathrm{~cd}=1 \& \mathrm{hl}=$ =en\&ct=clnk\&client= safari

Inglehart RF (2008) Changing Values among Western Publics from 1970 to 2006. West European Politics 31(1-2): 130-146.

International Labour Office (2004) Economic security for a better world. Geneva: Socio-Economic Security Programme, ILO.

Kelly C, Breinlinger S (1995) Identity and Injustice: Exploring Women's Participation in Collective Action. Journal of Community \& Applied Social Psychology 5(1): 41-57.

Kelly JE (1998) Rethinking Industrial Relations: Mobilization, collectivism, and long waves. London, New York: Routledge.

Learning and Skills Council (2007) Skills in England 2007 Volume 2: Research Report. Coventry: LSC.

Levine P, Flanagan C, and Gallay L (2008) The Millenial Pendulum: A new generation of voters and the prospects for a political realignment. Washington DC: New America Foundation.

Listhaug O, Aalberg T (1999) Comparative public opinion on distributive justice: A study of equality ideals and attitudes towards current policies. International Journal of Comparative Sociology 40(1): 117-140.

McAllister I, Clark J (2008) Trends in Australian Political Opinion: Results from the Australian Election Study, 1987-2007. Canberra: Australian Social Science Data Archive, Ausralan National University.

Mendelsohn M (2002) Canada's Social Contract: Evidence from Public Opinion. Ottawa: Canadian Policy Research Networks.

Osberg L, Smeeding T (2006) 'Fair' Inequality? Attitudes toward Pay Differentials: The United States in Comparative Perspective. American Sociological Review 71(3): 450-473.

Panagopoulos C, Francia PL (2008) Labour unions in the United States. Public Opinion Quarterly 72(1): 134-159. 
Patulny R (2004) Social capital and welfare: Dependency or Division? Examining Bridging Trends by Welfare Regime, 1981 to 2000. Social Policy Research Centre Discussion Paper No. 38. Sydney: University of New South Wales.

Peetz D (1998) Unions in a Contrary World: The future of the Australian trade union movement. Cambridge: Cambridge University Press.

Peetz D (2002) Sympathy for the devil? Australian unionism and public opinion. Australian Journal of Political Science 37(1): 57-80.

Pew Research Centre (2008) Inside the middle class: Bad times hit the good life. Washington DC: Pew Research Centre.

Pocock B (2003) The Work-Life Collision. Sydney: Federation Press.

Putnam RD (2000) Bowling Alone: The collapse and revival of American community. New York: Simon \& Schuster.

Realo A, Allik J, and Vadi M (1997) The hierarchical structure of collectivism. Journal of Research in Personality 31(1): 93-116.

Richardson C (2008) Working alone: The Erosion of Solidarity in Today's Workplace. New Labor Forum 17(3): 69-78.

Runciman WG (1972) Relative deprivation and social justice. Harmondsworth: Penguin.

Savage M (2002) Individuality and Class: The Rise and Fall of the Gentlemanly Social Contract in Britain. In: Zunz O, Schoppa LJ, and Hiwatari N (eds) Social contracts under stress: the middle classes of America, Europe, and Japan at the turn of the century. New York: Russell Sage, 47-65.

Savage M, Bagnall G, and Longhurst B (2001) Ordinary, Ambivalent and Defensive:

Class Identities in the Northwest of England. Sociology 35(4): 875-892.

Scott J (2000) Class and stratification. In: Payne G (ed.) Social Divisions. London: MacMillan, 20-54

Stephenson C, Stewart, P (2001) The whispering shadow: collectivism and individualism at Ikeda-Hoover and Nissan UK. Sociological Research Online, 6(3).

Torpe L (2003) Social capital in Denmark: A deviant case? Scandinavian Political Studies 26(1): 27-48.

Triandis HC (2001) Individualism-collectivism and personality. Journal of Personality, 69(6): 907-924. 
Valkenburg B (1995) Individualization, participation and solidarity. European Journal of Industrial Relations 1(1): 129-144.

Visser J (2007) Trade Union Decline and What Next: Is Germany a Special Case? Industrielle Beziehungen 14(2): 97-117.

Wellman B, Haase AQ, Witte J, and Hampton K (2001) Does the Internet increase, decrease, or supplement social capital? Social networks, participation, and community commitment. The American Behavioral Scientist, 45(3): 436-458.

Welzel C, Inglehart R, and Deutsch F (2005) Social Capital, Voluntary Associations and Collective Action: Which Aspects of Social Capital Have the Greatest 'Civic' Payoff? Journal of Civil Society 1(2): 121-146.

Wilkinson J, Bittman, M (2002) Volunteering: The human face of democracy. Social Policy Research Centre Discussion Paper No.114. Sydney: University of New South Wales.

Willmott H (1993) Strength is ignorance; slavery is freedom: Managing culture in modern organizations. The Journal of Management Studies 30(4): 515-552. Zoll R (1995) Failing to modernize? European Journal of Industrial Relations 1(1): 119-128. 